\title{
EFFICACY OF THE APHID PARASITOID DIAERETIELLA RAPAE (M'INTOSH) TO CONTROL BREVICORYNE BRASSICAE L., APHIS CRACCIVORA (KOCH) AND APHIS NERII BOYER AT SHARKIA GOVERNORATE, EGYPT
}

\author{
SALEH, A. A. A. \\ Plant Protection Research Institute, ARC, Giza, Egypt. \\ (Manuscript received 12 September 2013)
}

\begin{abstract}
Laboratory and semi- field experiments were carried out during 2013 winter season at Sharkia region to evaluate the performance of the parasitoid species Diaeretiella rapae (M'Intosh)for controlling Brevicoryne brassicae L., Aphis craccivora (Koch) and Aphis nerii Boyer infesting cabbage, faba bean and oleander plants. With the increase of parasitoid density, the percentage of parasitism increased to reach a maximum of 35.7, 29.7 and $25.2 \%$ for $D$. rapae at 11 parasitoid/200 aphids per jar in laboratory and a minimum of $11.30,7.30$ and $5.90 \%$ at one parasitoid per jar. Meanwhile, the highest percentage of parasitism were $92.20,83.20$ and $79.30 \%$ for $D$. rapae at 20 parasitoids/200aphids per cage in semi-field test, a minimum of $61.80,48.70$ and $41.50 \%$ recorded at five parasitoids per cage on $B$. brassicae, $A$. craccivora and $A$. nerii, respectively. On the other hand, with the increase of parasitoid density the percentage of emerged adults decreased to reach a maximum of 80.93, 75.54 and $63.85 \%$ for $D$. rapae at one parasitoid per jar in laboratory and $77.80,73.56$ and $57.90 \%$ at five parasitoids per cage in the field on $B$. brassicae, $A$. craccivora and $A$. nerii, respectively. With the increase of parasitoid density the fecundity of the parasitoid $D$. rapae increased (as number of mummies and emerged adults increased). The maximum numbers of mummies in the field were $185.60,166.4$ and 158.6 for $D$. rapae at 20 parasitoids per cage and minimum of $124.60,97.40$ and 83.0 mummies at five adults per cage. It is concluded that the parasitoid $D$. rapae could have the potential to be suitable biological control agent against $B$. brassicae, $A$. craccivora and $A$. nerii.

Key words: Diaeretiella rapae, Brevicoryne brassicae, Aphis craccivora, Aphis nerii, Release, Density.
\end{abstract}

\section{INTRODUCTION}

Biological control is a satisfactory program in integrated pest management. Control of insect pests by biocontrol agents is defined as the action of these agents that maintains a pest population at a lower level. Parasitism of aphid has been shown to be density dependent (Sinha and Singh1979 and Walker et al., 1984).

Diaeretilla rapae (Hymenoptera: Aphidiidae) is an important primary parasitoid of a wide range of aphid species including cabbage aphid Brevicoryne brassicae, cowpea aphid, Aphis craccivora and oleander aphid, Aphis nerii (Saleh, 2008 and 2012 and 
Maghraby 2012). Saleh and Gatwary (2007) recorded two primary parasitoids, $D$. rapae and Aphidius sp. on the oleander aphid $A$. nerii. To assure large numbers of parasitoids at a proper time for release it may be helpful to store their mummies until needed. Storage and release of the adult parasitoids are important when males are lacking. In this case, it is possible to hold virgin females after they have deposited male eggs and subsequently, mate with their own male progeny as mentioned by Ibrahim (1987). The increases in host density lead to a decrease in the proportion of hosts parasitized by the parasitoid, there was intra- specific competition among individuals of the female parasitoids in high density (Ralec et al. 2011 and Zahra et al. 2011).

The present study aims to evaluate the efficacy of $D$. rapae towards B. brassicae, $A$. craccivora and $A$. nerii under laboratory and semi field conditions.

\section{MATERIALS AND METHODS}

The present study was carried out at the laboratory, Plant Protection Research Institute, Sharkia Branch and the field of Kafr Sakr district, Sharkia Governorate during 2013winter season on cabbage, faba bean and oleander plants .

\section{a. In the laboratory:}

Laboratory culture of the two aphid species, $B$. brassicae and $A$. nerii were established on caged young seedlings of their hosts cabbage, faba bean and oleander plants or on detached young two leaves of cabbage and six leaves of oleander plant set flat on the bottom of clear plastic jar $(2 \mathrm{Kg})$. Meanwhile, faba bean seeds were grown in sandy clay soil in plastic pots. A stock culture of $A$. craccivora, established from aphids collected from faba and maintained in laboratory on young seedlings of faba bean.

Laboratory culture of the parasitoid, D. rapae adults was obtained from mummified Aphids the field parasitized cabbage, faba bean and oleander plants .Collected from Mummified aphids were placed singly, in small glass tubes until emergence of adult parasitoids which were fed on droplets of bee honey, at least for two generations were reared on appropriate host aphid species. Three experiments were carried out in clear plastic jar $(2 \mathrm{Kg}) \quad$ covered with muslin 25 jars for each experiment .In each experiment 200 nymphs of the host aphid species 200hosts of three aphids species ( $B$. brassicae, $A$. craccivora and $A$. nerii) exposed to different densities of the parasitoid: $1,3,5,7$ and 11 freshly emerged mated females/jar or glass chimney. Five replicates were performed for each parasitoid density under laboratory conditions $\left(20.0 \pm 1{ }^{\circ} \mathrm{C}\right.$ and $\left.70 \pm 4 \% \mathrm{RH}\right)$.

\section{b. In the semi - field:}

Three experiments were carried out under metal-framed cages $(100 \times 60 \times 60$ $\mathrm{cm}$ ) covered with muslin 20 cage for each experiment. Also young potted cabbage, 
faba bean and oleander seedlings bearing about 200 hosts (mixed ages)/ seedling were used. Using different densities of the parasitoid: 5, 10, 15 and 20 freshly emerged mated females / cage. In each experiment, females were supplied with droplets of bee honey for nutrition .Mated female parasitoids were gently introduced into each cage and kept for 24h., then the parasitoids were removed and the hosts were left until being mummified. Mummies were gently placed with parts of cabbage leaves, on a moistened filter paper in marked Petri-dishes. The mummies were observed until adults' emergence. Adults were recorded and sexed. Five replicates were performed for each parasitoid density (20 plants in each experiment were used) under semi- field conditions ( $18.0 \pm 1^{\circ} \mathrm{C}$ and $\left.68 \pm 5 \% \mathrm{RH}\right)$.

Statistical analysis: Data were subjected to statistical analyses using a software package CoStat $^{\circledR}$ Statistical Software (2005) a product of Cohort Software, Monterey, California.

\section{RESULTS AND DISCUSSION}

\section{Relation of parasitoid densities on parasitization rate:}

\section{a. In the laboratory:}

Table 1 show that the $D$. rapae different densities influenced on the percentage of emergence of adult parasitoids, giving maximum percentage i.e. 80.93, 75.54 and $63.85 \%$ at one parasitoid per jar and a minimum ones i.e. $69.33,49.03$ and $43.99 \%$ at 11 parasitoids per jar on $B$. brassicae, $A$. craccivora and $A$. nerii, respectively. There were significant differences between the percentage of parasitism with one parasitoid per jar and each of 3, 5, 7 and 11 parasitoids per jar. The increase of parasitoid density increased the rate of parasitism and the number of parasitized aphids. The maximum percentage of parasitism were $35.7,29.7$ and $25.2 \%$ for $D$. rapae at 11 parasitoid per jar and a minimum of $11.30,7.30$ and $5.9 \%$ were recorded at one parasitoid per jar on $B$. brassicae, $A$. craccivora and $A$. nerii, respectively. The increase of the number of parasitoid increased the percentages of the parasitism, while the percentage emergence of adult parasitoids decreased with the same aphid species, respectively.

The maximum numbers of mummies in laboratory were $71.4,59.4$ and 50.40 for $D$. rapae at 11 parasitoids per jar and minimum of 22.6, 14.6 and 11.8 mummies at one parasitoid per jar. Also, the maximum numbers of emerged adults were 49.4, 29.2 and 22.2 for $D$. rapae at 11 parasitoids per jar and minimum of $18.2,11.0,7.6$ at one parasitoid per jar on B. brassicae, A. craccivora and A. nerii, respectively (Fig. 1, 2 \&3).

In general, differences in the density of host aphids and the respective parasitoids influence the behavioral characteristics. A higher density of parasitoid may increase the proportion of male progeny, because male need less food resources than females (Jones et al. 2003). 
Preference of certain host species has been demonstrated in laboratory studies where parasitoids more often oviposit in some species than in other, when both the host species are offered separately or simultaneously (Chau and Mackauer, 2001). On the other hand, Gently and Barbosa (2006) reported that leaf epicuticular wax plays an important role on the movement, foraging behavior and attack efficiency of $D$. rapae. However, AbdulRehman and Powell (2010) mentioned that aphid parasitoids have considerable potential as biological control agents but their efficiency is dependent upon their presence in the right place at the right time and right host :parasitoid ratio . Understanding parasitoid behavior, together with identification of physical and chemical signals regulating the behavior, is providing exciting opportunities for manipulation of parasitoids in the field, as populations introduced through inundative releases.The parasitoids having selectively bred to attack specific hosts and then primed to an appropriate plant volatiles as foraging cues before release, could be used in inundative releases.

\section{b. In the semi-field:}

The maximum numbers of mummies in the semi- field experiments were $185.60,166.4$ and 158.6 for $D$. rapae at 20 parasitoids per cage and minimum of $124.60,97.40$ and 83.0 mummies at density of five adults. The maximum number of emerged parasitoids per cage $136.40,88.8$ and 63.40 for $D$. rapae at 20 parasitoids per cage and minimum of $96.20,71.60$ and 47.8 at five parasitoid per cage on $B$. brassicae, $A$. craccivora and $A$. nerii, respectively (Fig. 4, 5 and 6).

Data in Table 2 indicated that the parasitoid density had influenced the percentage of parasitism where the increase of parasitoid density the rate of parasitism and the number of parasitized aphid increased. The maximum percentages of parasitism were $92.20,83.2$ and $79.3 \%$ for $D$. rapae at 20 parasitoid per cage and a minimum of $61.80,48.70$ and $41.5 \%$ was recorded at five parasitoids per cage on $B$. brassicae, $A$. craccivora and $A$. nerii, respectively. Also, the highest percentages for emergence of adult parasitoids were $77.80,73.56$ and $57.9 \%$ recorded at five parasitoids per cage on $B$. brassicae, $A$. craccivora and $A$. nerii, respectively.

However, Heraky and Abou El-Ezz 1970 reported that $D$. rapae played the major role towards suppressing $B$. brassicae population. With the increase of parasitoid density the fecundity of the parasitoids $D$. rapae as number of mummies and emerged adults increased. The previous results indicated that the percentage of parasitism were increased at lower host densities as the parasitoid was enable to attack high number of its host at increased densities Ragab and Ghanium 1997.

These findings agree with those of El-Naggar et al. 2008 who mentioned that parasitoid density in relation to host density had influenced percentage of parasitism. Highest percentage reached $91.40 \%$ at $16 D$. rapae female parasitoids per cage while the minimum was $55.6 \%$ at one female per cage. The percentage of parasitism 
increased with increase of numbers of parasitoid. However, Zahra et al. (2011) mentioned that the functional response and rate of parasitism by $D$. rapae on different densities of Diuraphis noxia (Mordvilho).The increases in host density lead to a decrease in the proportion of hosts parasitized by the parasitoid, there was intraspecific competition among individuals of the female parasitoids in high density .

Table 1 . Effect of parasitoid density on the number of B. Brassicae, A. craccivora and $A$. nerii mummies, percentages of parasitism and adults emergence under laboratory conditions .

\begin{tabular}{|c|c|c|c|c|c|c|}
\hline \multirow[b]{3}{*}{$\begin{array}{l}\text { Parasitoid } \\
\text { density }\end{array}$} & \multicolumn{6}{|c|}{ Mean \pm SD } \\
\hline & \multicolumn{2}{|c|}{ B. Brassicae } & \multicolumn{2}{|c|}{ A. craccivora } & \multicolumn{2}{|c|}{ A. nerii } \\
\hline & $\begin{array}{l}\text { Percentage of } \\
\text { parasitism }\end{array}$ & $\begin{array}{c}\text { Percentage of } \\
\text { adult } \\
\text { emergence }\end{array}$ & $\begin{array}{l}\text { Percentage of } \\
\text { parasitism }\end{array}$ & $\begin{array}{c}\text { Percentage of } \\
\text { adult } \\
\text { emergence }\end{array}$ & $\begin{array}{c}\text { Percentage of } \\
\text { parasitism }\end{array}$ & $\begin{array}{c}\text { Percentage of } \\
\text { adult } \\
\text { emergence }\end{array}$ \\
\hline $1+$ & $\begin{array}{c}11.30 \pm \\
1.78 \mathrm{~d}\end{array}$ & $\begin{array}{c}80.93 \pm \\
2.07 a\end{array}$ & $\begin{array}{c}7.3 \pm \\
0.54 \mathrm{~d}\end{array}$ & $\begin{array}{c}75.54 \pm \\
1.06 \mathrm{a}\end{array}$ & $\begin{array}{l}5.9 \pm \\
1.55 \mathrm{e}\end{array}$ & $\begin{array}{c}63.85 \pm \\
2.22 \mathrm{a}\end{array}$ \\
\hline $3 q$ & $\begin{array}{l}23.2 \pm \\
1.65 \mathrm{c}\end{array}$ & $\begin{array}{l}76.66 \pm \\
2.71 \mathrm{ab}\end{array}$ & $\begin{array}{l}14.6 \pm \\
1.25 \mathrm{c}\end{array}$ & $\begin{array}{r}69.13 \pm \\
3.78 \mathrm{a}\end{array}$ & $\begin{array}{l}10.9 \pm \\
1.59 \mathrm{~d}\end{array}$ & $\begin{array}{l}60.09 \pm \\
3.85 \mathrm{ab}\end{array}$ \\
\hline 5 우 & $\begin{array}{l}28.8 \pm \\
1.96 \mathrm{~b} \\
\end{array}$ & $\begin{array}{l}74.43 \pm \\
2.44 a b \\
\end{array}$ & $\begin{array}{l}20.0 \pm \\
0.91 b\end{array}$ & $\begin{array}{l}58.91 \pm \\
3.60 \mathrm{~b} \\
\end{array}$ & $\begin{array}{l}16.9 \pm \\
2.08 c\end{array}$ & $\begin{array}{l}53.82 \pm \\
2.99 \mathrm{bc} \\
\end{array}$ \\
\hline 7 우 & $\begin{array}{l}31.2 \pm \\
1.41 \mathrm{ab}\end{array}$ & $\begin{array}{c}70.71 \pm \\
3.99 \mathrm{~b}\end{array}$ & $\begin{array}{l}23.5 \pm \\
1.33 b\end{array}$ & $\begin{array}{l}55.67 \pm \\
3.19 b c\end{array}$ & $\begin{array}{c}20.1 \pm \\
1.06 \mathrm{~b}\end{array}$ & $\begin{array}{l}47.13 \pm \\
1.68 \mathrm{~cd}\end{array}$ \\
\hline 11 우 & $\begin{array}{l}35.7 \pm \\
1.91 \mathrm{a}\end{array}$ & $\begin{array}{c}69.33 \pm \\
1.99 \mathrm{~b}\end{array}$ & $\begin{array}{l}29.7 \pm \\
1.61 \mathrm{a}\end{array}$ & $\begin{array}{c}49.03 \pm \\
1.29 \mathrm{C}\end{array}$ & $\begin{array}{c}25.2 \pm \\
1.29 \mathrm{a}\end{array}$ & $\begin{array}{c}43.99 \pm \\
1.29 \mathrm{~d}\end{array}$ \\
\hline $\mathrm{LSD}_{0.05}$ & 4.7429 & 8.0943 & 3.5066 & 8.3815 & 2.8540 & 7.2903 \\
\hline$P$ & $0.0000 * * *$ & $0.0487^{*}$ & $0.0000 * * *$ & $0.0000 * * *$ & $0.0000 * * *$ & $0.0487^{*}$ \\
\hline
\end{tabular}

Data expressed as Mean \pm S. D. $\quad *=p \leq 0.05 \quad * *_{-} * * *=p \leq 0.01$

Mean under each variety having different letters in the same raw denote a significant different $(p \leq 0.05)$.

Table 2. Effect of parasitoid density on the number of $B$. Brassicae, $A$. craccivora and $A$. nerii mummies, percentages of parasitism and adults emergence under semi-field conditions.

\begin{tabular}{|c|c|c|c|c|c|c|}
\hline \multirow[b]{3}{*}{$\begin{array}{l}\text { Parasitoid } \\
\text { density }\end{array}$} & \multicolumn{6}{|c|}{ Mean \pm SD } \\
\hline & \multicolumn{2}{|c|}{ B. Brassicae } & \multicolumn{2}{|c|}{ A. craccivora } & \multicolumn{2}{|c|}{ A. nerii } \\
\hline & $\begin{array}{c}\text { Percentage of } \\
\text { parasitism }\end{array}$ & $\begin{array}{c}\text { Percentage of } \\
\text { adult } \\
\text { emergence }\end{array}$ & $\begin{array}{c}\text { Percentage of } \\
\text { parasitism }\end{array}$ & $\begin{array}{c}\text { Percentage of } \\
\text { adult } \\
\text { emergence }\end{array}$ & $\begin{array}{c}\text { Percentage of } \\
\text { parasitism }\end{array}$ & $\begin{array}{c}\text { Percentage of } \\
\text { adult } \\
\text { emergence }\end{array}$ \\
\hline \multirow{2}{*}{5 우 } & $61.80 \pm$ & $77.80 \pm$ & $48.7 \pm$ & $73.56 \pm$ & $41.5 \pm$ & $57.91 \pm$ \\
\hline & $1.87 \mathrm{~d}$ & $0.75 a$ & $1.47 \mathrm{~d}$ & $1.91 \mathrm{a}$ & $3.91 \mathrm{~d}$ & $1.98 \mathrm{a}$ \\
\hline \multirow{2}{*}{10 + } & $77.40 \pm$ & $73.63 \pm$ & $65.6 \pm$ & $69.92 \pm$ & $61.8 \pm$ & $47.3 \pm$ \\
\hline & $2.38 c$ & $0.34 b$ & $3.54 \mathrm{c}$ & $2.24 \mathrm{a}$ & $1.91 \mathrm{c}$ & $1.06 \mathrm{~b}$ \\
\hline \multirow{2}{*}{15 우 } & $85.60 \pm$ & $74.91 \pm$ & $75.2 \pm$ & $62.6 \pm$ & $70.1 \pm$ & $43.33 \pm$ \\
\hline & $1.33 \mathrm{~b}$ & $0.86 a b$ & $2.63 \mathrm{~b}$ & $0.37 \mathrm{~b}$ & $2.28 \mathrm{~b}$ & $1.97 \mathrm{bc}$ \\
\hline \multirow{2}{*}{209} & $92.80 \pm$ & $74.80 \pm$ & $83.2 \pm$ & $54.52 \pm$ & $79.3 \pm$ & $39.92 \pm$ \\
\hline & $1.02 \mathrm{a}$ & $1.46 a b$ & $2.43 \mathrm{a}$ & $0.62 \mathrm{c}$ & $1.77 a$ & $2.35 c$ \\
\hline $\mathrm{LSD}_{0.05}$ & $5.0834 * *$ & 3.2992* & 7.8779 & 4.5506 & 7.8415 & 5.7142 \\
\hline
\end{tabular}

Mean under each variety having different letters in the same raw denote a significant different $(p \leq 0.05)$. 


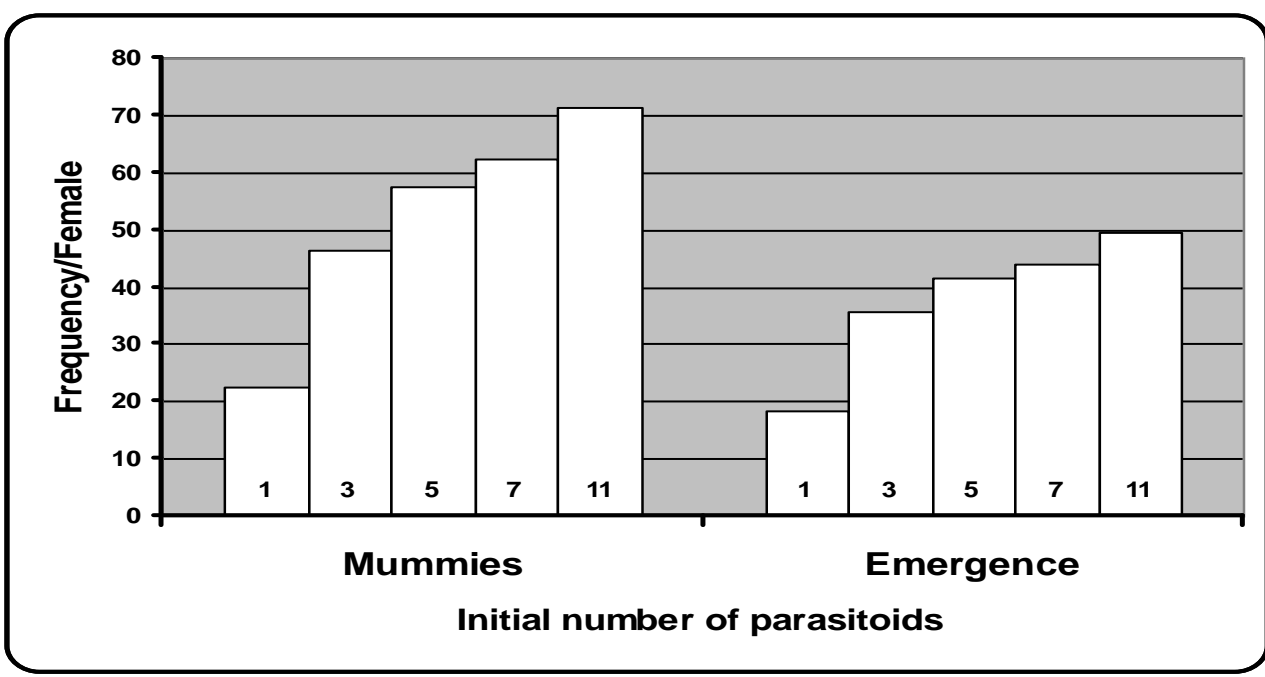

Fig. 1. Fecundity of the parasitoid of $D$. rapae as number of mummies formed from $B$. brassicae at its different densities under laboratory conditions.

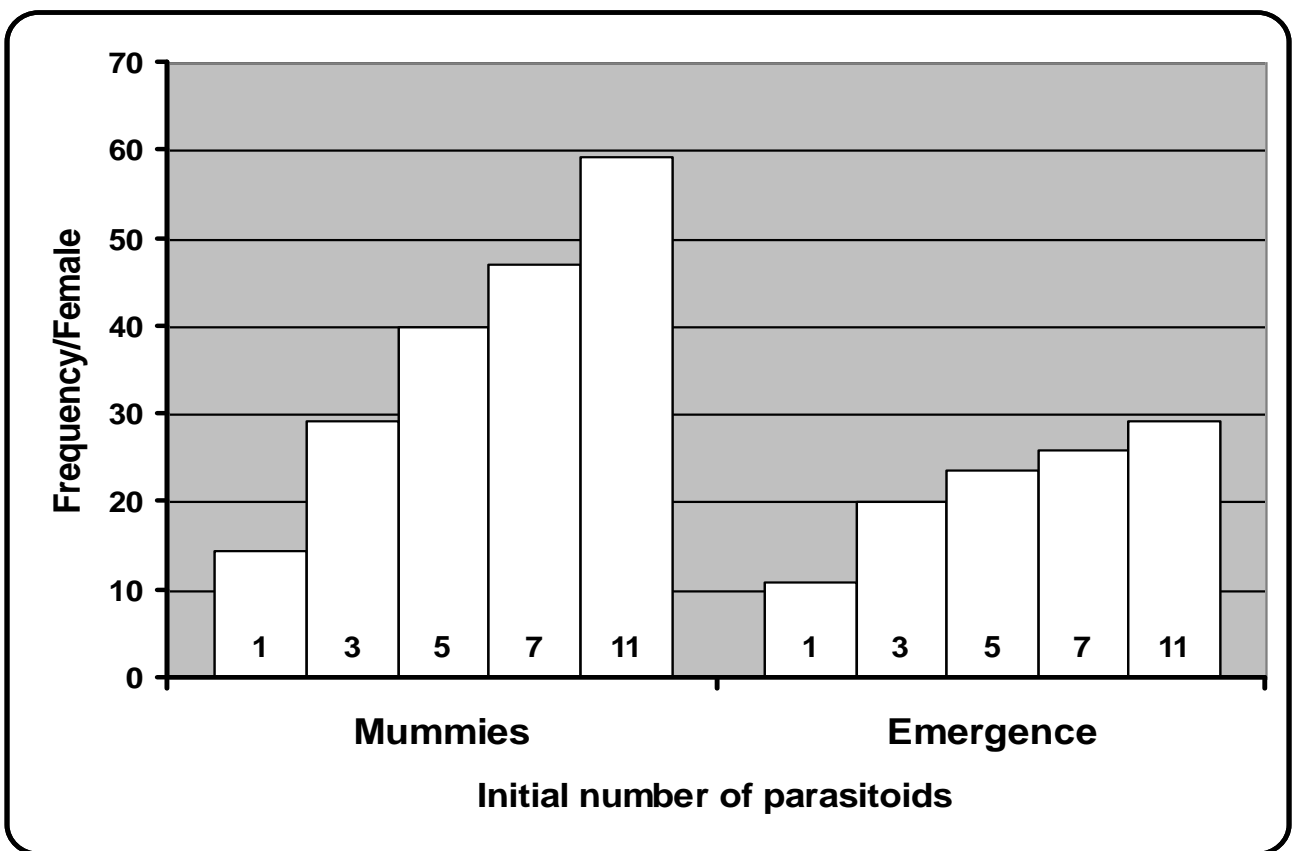

Fig. 2. Fecundity of the parasitoid of $D$. rapae as number of mummies formed from A. craccivora at its different densities under laboratory conditions 


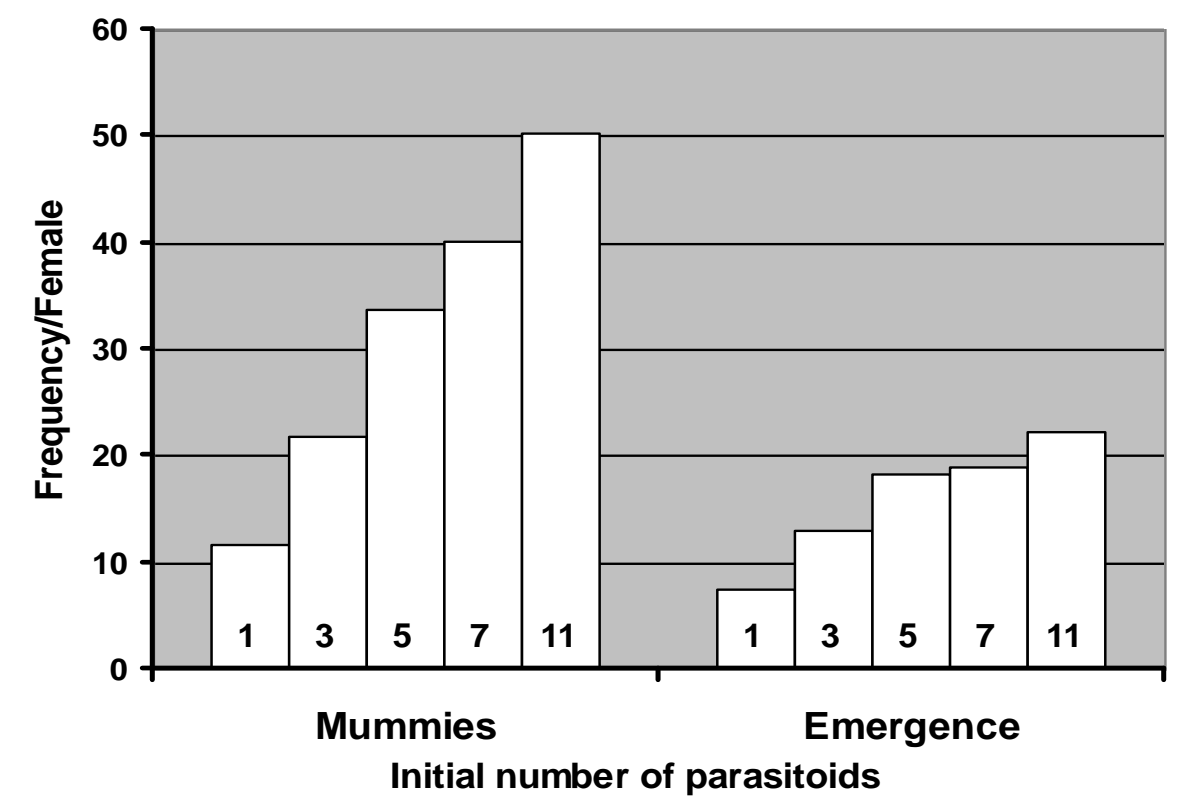

Fig. 3. Fecundity of the parasitoid of $D$. rapae as number of mummies formed from A. nerii at its different densities under laboratory condition.

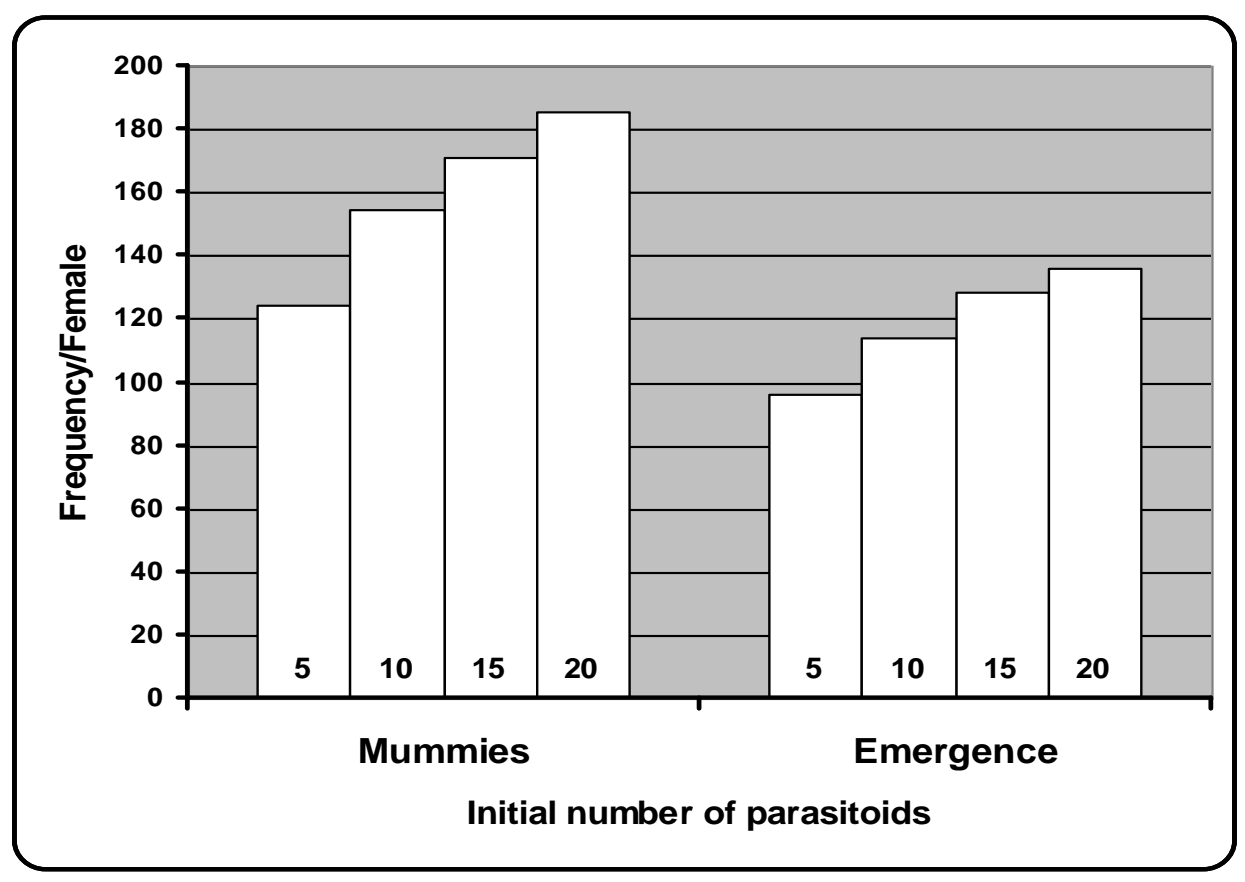

Fig. 4. Fecundity of the parasitoid of $D$. rapae as number of mummies formed from B. brassicae at its different densities under semi-field conditions. 


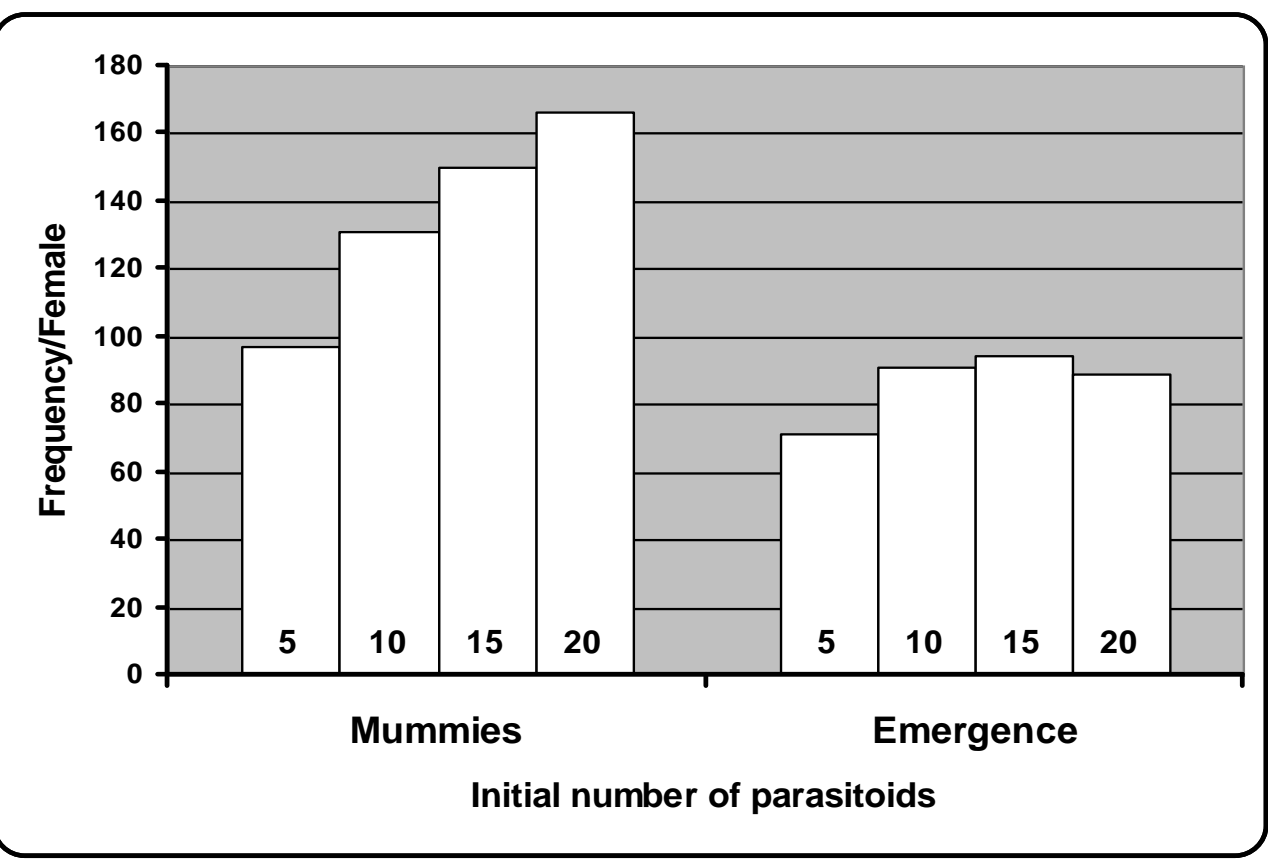

Fig. 5. Fecundity of the parasitoid of $D$. rapae as number of mummies formed from A. craccivora at its different densities under semi-field conditions.

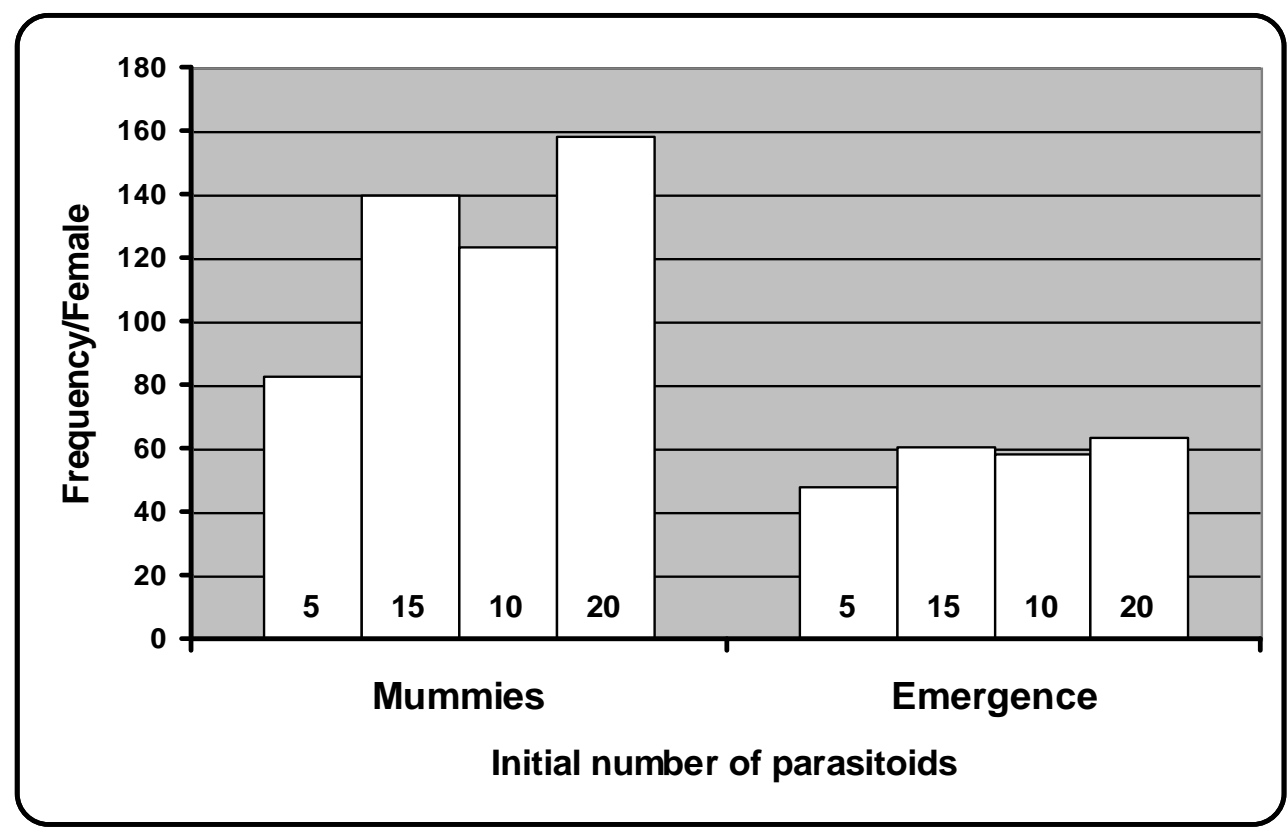

Fig. 6. Fecundity of the parasitoid of D. rapae as number of mummies formed from $A$. nerii at its different densities under semi-field conditions. 


\section{REFERENCES}

1. Abdul Rehman and Powell, W. 2010. Host selection behavior of aphid parasitoids (Aphidiidae : Hymenoptera ). J.Plant Breeding and Crop Science 2(10) 299- 311 .

2. Chau , A and Mackauer, M. 2001. Preference of the aphid parasitoid Monoctonus paulensis (Hymenoptera: Braconidae, Aphidiinae) for different aphid species:Female choice and offspring survival .Biol.Control.20(1):30-38.

3. CoStat Statistical Software. 2005. Microcomputer program analysis version, 6. 311. CoHort Software, Monterey, California.

4. El-Naggar, E. M., Abou El-Nagar, A. M., Ghanim, A. A. And Saleh, A. A. 2008. Mass production and field application of some aphid natural enemies. Egypt. J. Agric. Res. 86 (2): 623-624.

5. Gently, GL and Barbosa, P. 2006. Effects of leaf epicuticular wax on the movement, foraging behavior, and attack efficacy of Diaeretiella rapae Entomol., Exp.Appl.,121:115-122.

6. Herakly, F. A. and Abou El-Ezz, A. 1970. Seasonal abundance and natural enemies of the cabbage aphid, Brevicoryne brassicae.L..Agric.,Res., Rev.,48:119-122.

7. Ibrahim, A. M. A. 1987. Studies on aphidophagous parasitoids with special reference to Aphidius uzbekistanicus (Luz) (Hymenoptera: Aphidiidae). Ph. D. Thesis, Fac. of Agric., Cairo Univ. pp. 202.

8. Jones, D. B., Giles, k.L. , Berberet, R.C ., Royer, T.A. , Elliott, N.C. and Payton 2003. Functional response of an introduced parasitoid and an indigenous parasitoid on greenbug at four temperature .Environ.Entomol.32, 425-432.

9. Maghraby, H. M. 2012. Studies on the parasitoid Diaeretiella rapae on some aphid species in Sharkia Governorate. M. Sc. Thesis Fac. of Agric. Moshtohor Univ., 222pp.

10. Ragab, M. E. and Ghanim, A. A. 1997. Effect of different parasite/host ratio between Trioxys angelicae Hal, (Hymenoptera: Aphidiidae) and its host Aphis craccivora Koch.(Homoptera: Aphdidae) on the percentages of parasitism and population development. J. Agric. Sci. Mansoura Univ., 27 (4): 2619 - 2002.

11. Ralec, A., Ribule, A., Barragan, A. and Outerman, Y. (2011): Host range limitation caused by incomplete host regulation in an aphid parasitoid. J. Insect Physio. 57 (3): 363-371.

12. Saleh, A. A. A. and Gatwary, W. G. T. 2007. Seasonal abundance of the oleander aphid, Aphis nerii Boyer de Fonscolombe (Homoptera: Aphididae) in 
relation to the primary and hyperparasitoids on Difla in Egypt. J. product. \& Dev., 12 (2): 709-730.

13. Saleh, A. A. A. 2008. Ecological and biological studies of Diaeretiella rapae (M'Intosh) (Hymenoptera: Aphidiidae) the parasitoid of some aphid species in Egypt. Egypt. J. Biol. Pest Cont.,18 (1):33-38.

14. Saleh, A. A. A. 2012. Evaluation of release of Diaeretiella rapae (M' Intosh) for controlling the cruciferous aphid Brevicoryne brassicae L. on cauliflower plants at Sharkia Governorate, Egypt. J. Plant Prot. and Path. Mansoura Univ. 3 (3): 307-318.

15. Sinha,T. B. and Singh, R. 1979. Studies on the bionomics of Trioxys indicus SubbaRao and Sharma (Hymenoptera: Aphidiidae) :A parasitoid of Aphis craccivora Koch (Hymenoptera: Aphidiidae) the area of discovery of parasitoid. Ze tschrift fur Angewandte Entomol.,89 (2):173-178.

16. Walker, G. P., Nault, L. R. and D. E. Simonet. 1984. Natural mortality factors acting on potato aphid (Macrosiphum euphorbiae) populations in processing tomato field in Ohio. Environmental Entomol., 13, 724-732.

17. Zahra , T. , Talebi , A . A and Rakhshani, E. 2011. The foraging behavior Diaeretiella rapae (Hymenoptera: Braconidae) on Diuraphis noxia (Hymenoptera : Aphidiidae ) .Arch. Biol. Sci.,Belgrade, 63(1),225-2 


\section{كفاعة الطفيل Diaeretiella rapae (M'Intosh) فى مكافحة من الصلبيات}

Brevicoryne brassicae L.

Aphis nerii Boyer

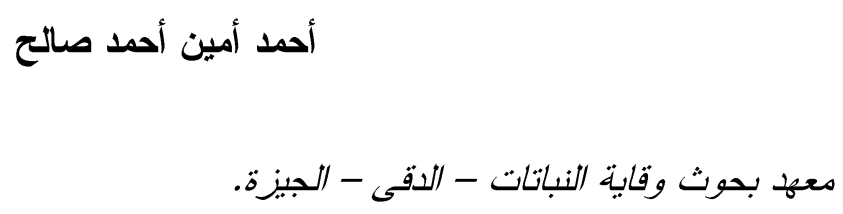

أجريت تجارب معملية وحقلية خلال الموسم الشتوى ب ا ـ ب فى محافظة الثرقية لتقييم أداء

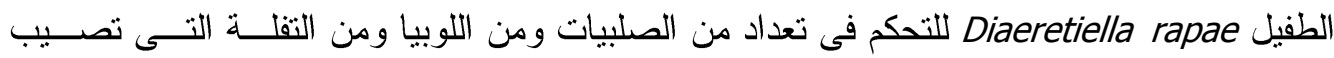
نباتات الكرنب و الفول البلدى ونباتات التقلة ـ و أوضحت الدراسة أن نسبة التطفل تزداد بزيادة الكثافة

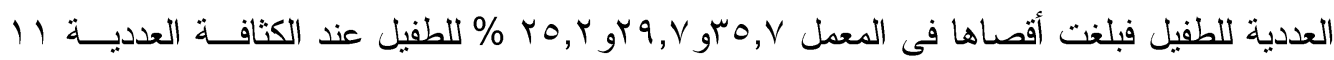

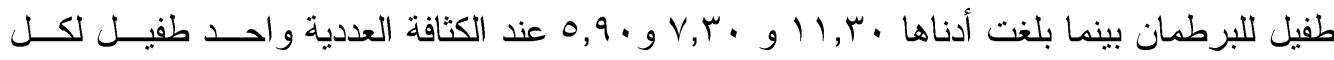
برطمان .

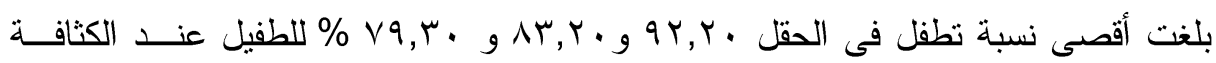

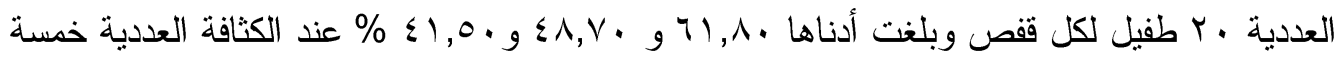

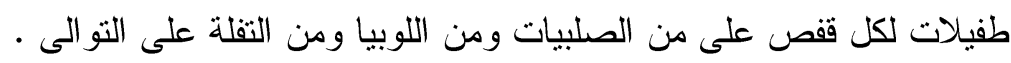

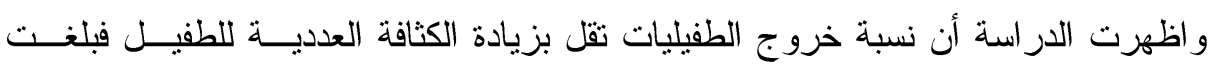

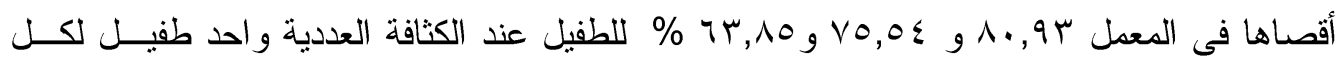

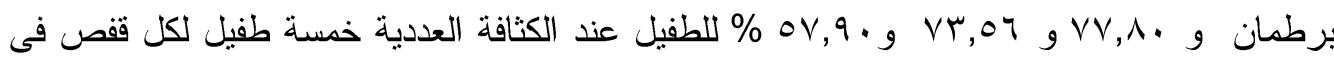

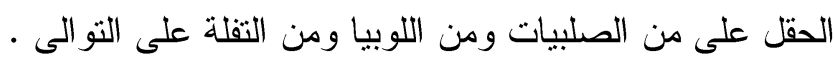

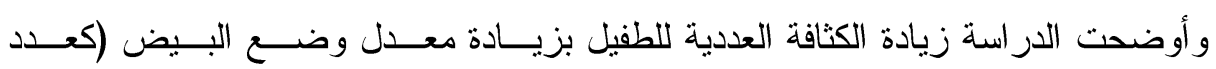

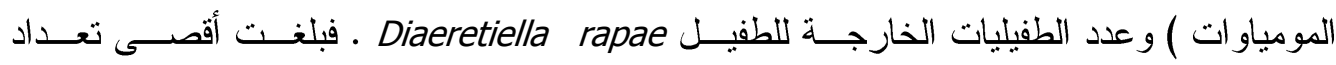

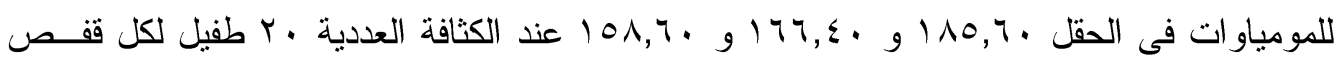

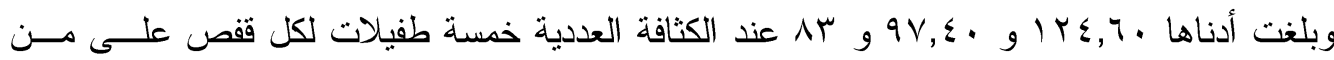

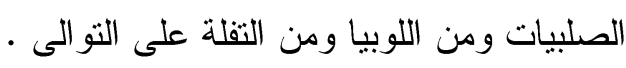

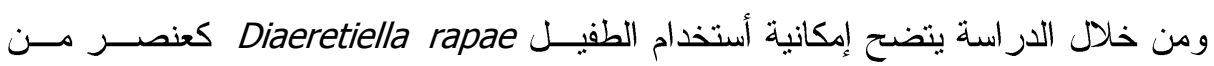

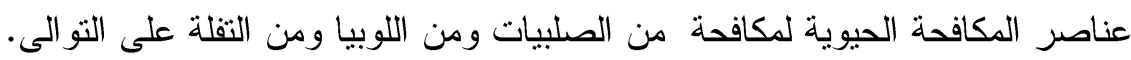

